\title{
Desenho digital: workshop de projeto para um sistema expositivo móvel
}

\author{
Digital design: workshop project for a mobile exhibition system
}

> VIZIOLI, Simone Helena Tanoue

Instituto de Arquitetura e Urbanismo

Universidade de São Paulo, Brasil

simonehtv@sc.usp.br

$>\quad$ LANCHA, Joubert Jose

Instituto de Arquitetura e Urbanismo

Universidade de São Paulo, Brasil

joubertlancha@gmail.com
> CASTRAL, Paulo Cesar

Instituto de Arquitetura e Urbanismo

Universidade de São Paulo, Brasil

pcastral@sc.usp.br

> MEDEIROS, Givaldo Luiz

Instituto de Arquitetura e Urbanismo

Universidade de São Paulo, Brasil

givaldo@sc.usp.br

\begin{abstract}
This article is part of the studies and activities that are being developed in the Support Center for Research in Language Arts in Architecture and City, belonging to the Institute for Architecture and Urbanism, University of São Paulo (N.ELAC / IAU.USP). The main purpose of this research was to discuss the role of traditional media and new digital media of drawing in the projective process and in a construction of the architectural thought. This experimentation performed a very important role in supporting research within the design activities, because of the various possibilities in working the multiple logical thinking in a new cognitive process. This research represents a space for reflection of the process of reframing the act of drawing and in the constitution of a new perception.
\end{abstract}

Keywords: keywords; keywords; keywords; keywords; keywords.

\section{Introdução: o desenho analógico e digital}

Este artigo é parte dos estudos e atividades que vêm sendo desenvolvidos no Núcleo de Apoio à Pesquisa em Estudos de Linguagem em Arquitetura e Cidade do Instituto de Arquitetura e Urbanismo da Universidade de São Paulo (N.ELAC/IAU.USP), que desenvolve pesquisas relacionadas à Linguagem e Representação dando ênfase aos processos cognitivos e projetuais presentes tanto na percepçáo da cidade e da arquitetura.

Vive-se atualmente um momento marcado por um lado, pela abundância dos meios de comunicação visual, e por outro, pelo questionamento dos papéis das representações gráficas. Embora novas ferramentas de representação e novos meios digitais projetivos estejam continuamente em surgimento, o desenhar como expressão de uma ideia - o gesto como uma linguagem comprometida com o dinamismo intrínseco ao processo criativo - segue sendo um campo de experimentação enriquecedor. Com os novos aparatos (tablets) é possível desenhar além do alcance da mão. Este texto procura identificar as experimentaçóes e percepçóes que os desenhos mantêm por meio dessas ferramentas digitais. Mitchell e McCullough (1991) ressaltam que, embora as habilidades do olho-mão aparentemente tenham menor importância nas operaçôes com computadores, as capacidades humanas de percepção e seleção crítica das informaçôes tornam-se, neste momento, mais vitais do que nunca.

O desenho é considerado uma linguagem gráfica que concede à representação gráfica o valor de um mediador e de um veículo que materializa e faz possível o conhecimento projetual, da mesma forma que a linguagem verbal (Uria, 2007). Esboçar permanecerá como um comportamento chave na geração de ideias iniciais projetuais. (Kavakli, 1998). Inúmeros são os pesquisadores que investigam o tema, entre eles, tem-se Gouveia (1998), Tversky (2002), e Zafer (2006), para quem os esboços têm na ambiguidade um de seus fatores-chaves, isto porque estas representaçôes permitem novas possibilidades e também novas reinterpretaçóes do projeto. Lugt (2001), Teresa Eça (2003) e Ortega (2000) procuram classificar os croquis, respectivamente, por sua tipologia, pela função que ocupam no processo projetivo e pelo objetivo que atendem. Laseau (1982) discute o desenho pelo seu desenhador - emissor e pelo receptor da mensagem. O croqui é a rápida transcrição das ideias que surgem, Pelayo (2002) e Ortega (2000) ressaltam que não se trata de um desenho acabado, mas sim, de uma transmissão instantânea do pensamento para o papel. São recorrentes as comparaçóes entre o uso de desenho de processo feito à mão e aquele desenvolvido no computador. Podem ser citados os trabalhos de Elliott e Hearst (2002), Righi (2009), e Celani (2007) que analisam como a tecnologia interfere no processo projetivo.

\section{Processos cognitivos}

Para o desenvolvimento deste trabalho adotou-se o modelo de Chan (1990) que descreve os processos cognitivos do projeto arquitetônico. $\mathrm{O}$ início de um projeto pode ser dar por meio de uma problematização e seus objetivos. A análise desses objetivos levam à identificação de limites para a resoluçáo da questão colocada, que por sua vez, podem ser divididos em dois tipos: as limitaçóes globais que consistem nas regras e condiçóes pré-existentes e independem 


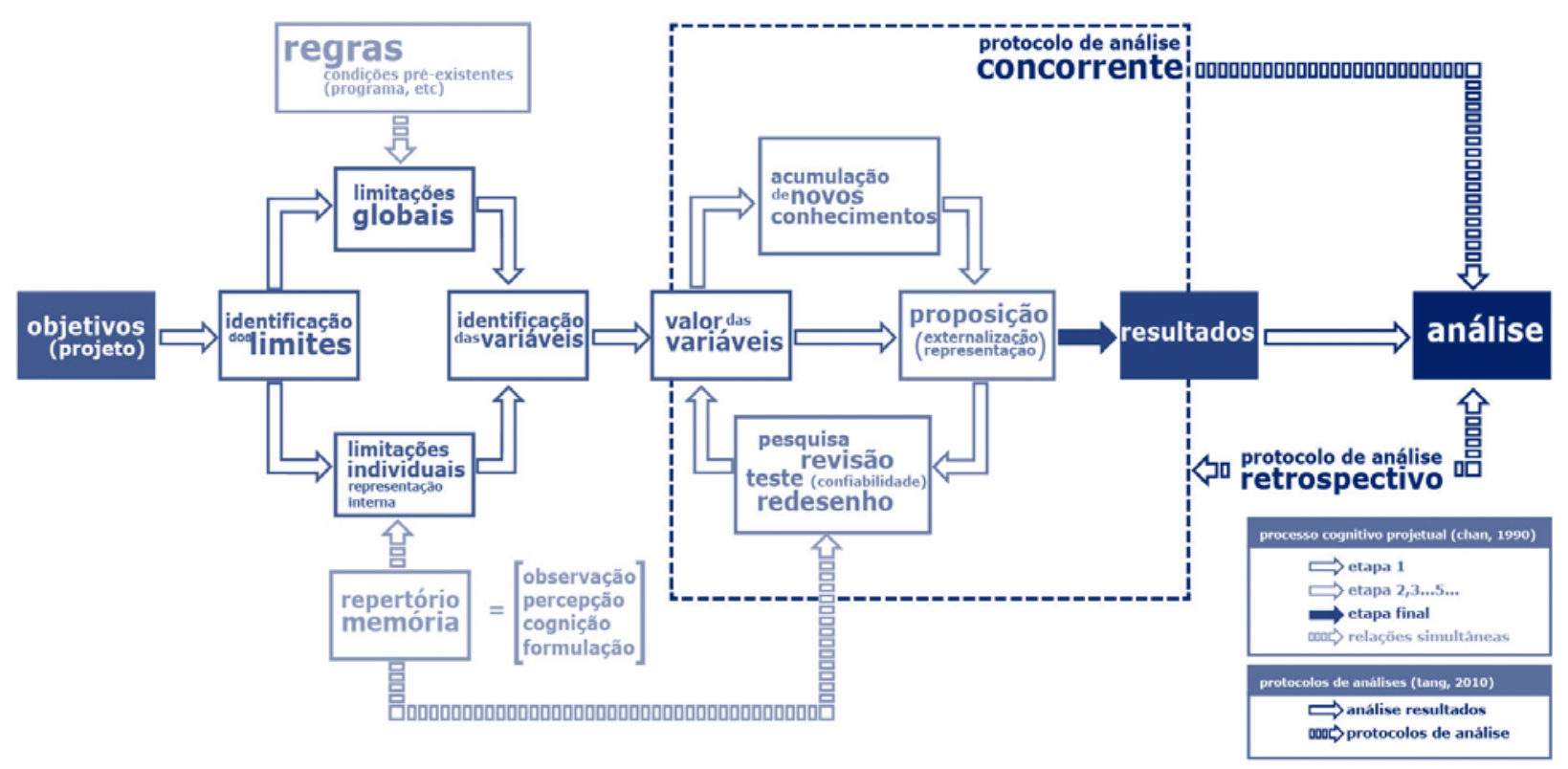

Figura l: esquema metodológico no processo cognitivo de projetos arquitetônicos e protocolos de análise. Fonte: baseado em esquema de (Chan, 1990) adaptado pelos autores, 2014.

de interpretação e as limitaçóes individuais, estas mais complexas. As limitaçóes individuais dependem do autor do projeto, de seu repertório, construído por uma memória alimentada por açóes como a observação, a percepção e a cognição de fatos inseridos em diferentes contextos. Esta etapa individual do processo pode ser definida como a representação interna da busca pela solução do problema. A partir da identificação dessas limitações é possível elencar as variáveis de projeto e atribuir valores a elas, buscando-se uma proposição. Na etapa da proposição a ideia é apresentada por uma representaçáo externa, que, num primeiro momento é feito por meio de desenhos rápidos. Esses croquis permitem o desenvolvimento das próximas etapas: teste e revisão dos conceitos iniciais. Uma vez feita a primeira proposição, pesquisas complementares requalificam o valor das variáveis identificadas no momento anterior. Esse processo é qualitativamente melhorado com a acumulação de novos conhecimentos que por sua vez, resultam em novas proposiçóes. Esse último ciclo acontece tantas vezes o quanto forem necessárias, até que se apresente um resultado final. (Figura 1)

\section{Workshop}

Este artigo discute os resultados do Workshop "Sistema Expositivo Móvel”, objetivando questionar o papel dos novos meios digitais de desenho, no processo projetivo e na formação do pensamento arquitetônico, utilizando-se somente ferramentas de desenho livre digitais.

O workshop foi organizado e ministrado por docentes do IAU.USP com duração de 60 horas, e desenvolvido no Campus Sáo Carlos (SP), em setembro de 2012. Participaram um total de
24 alunos, do Curso de Arquitetura e Urbanismo do IAU.USP (CAU.IAU) de diversos períodos, que foram divididos em três grupos de trabalhos. O objeto do exercício foi o desenvolvimento de um sistema de suporte a exposiçóes, cujo formato, caráter e localização são indeterminados, porém inscritos no contexto do sítio do próprio Campus. Buscou-se um contraponto à centralidade atual, fortalecendo as diversas áreas de vivência por meio de uma ocupação polinucleada. O projeto tinha como premissa abrigar diferentes conteúdos e mídias. A partir de uma identificação dos limites, observação e cognição individual do sítio e discussão coletiva das possibilidades, cada equipe concebeu inicialmente um sistema comum, para então desenvolver individualmente uma situação específica de implantação (uma para cada membro da equipe). Os equipamentos implantados possuem uma área aproximada de $25 \mathrm{~m}^{2}$.

Para tanto, os alunos foram limitados a utilizar apenas tablets (opacas e gráficas) e os softwares: SketchBook Pro ${ }^{\circledR}$, Paper by $53^{\circledR} \mathrm{e}$ Adobe Photoshop ${ }^{\circledR}$ e Adobe Photoshop Touch ${ }^{\circledR}$. Em nenhum momento foi permitido o uso do papel e lápis, bem como de programas paramétricos ou vetoriais com uso de teclado e mouse. Esta limitação teve como objetivo evidenciar tanto as características dos croquis, como verificar as potencialidades das ferramentas disponibilizadas. Permitiu-se, no entanto, a utilização de qualquer conteúdo que os equipamentos possibilitassem, ou seja, a partir da conexáo com uma rede de internet poderiam incorporar imagens de referências projetuais bem como dados de geoprocessamento, e a partir das câmeras das tablets portáteis poderiam capturar imagens do sitio do projeto como material de análise e projetação.

Pretendeu-se adotar a experimentação como laboratório de observação das atividades cognitivas no processo projetivo, como campo possível para flagrar fatos que contribuíssem para o atual debate acerca da permanência, no meio digital, de um modo de desenho próximo ao pensamento. Um campo de investigação onde 


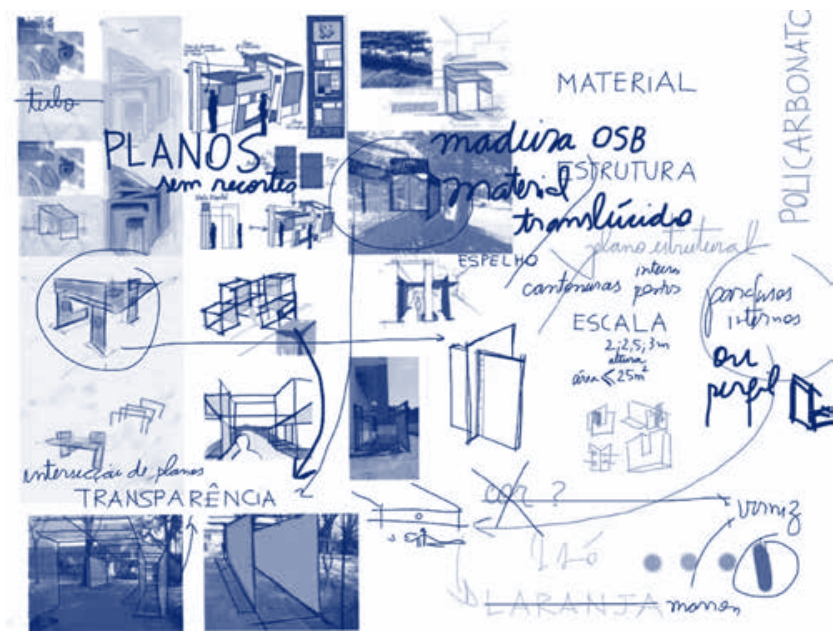

Figura 2: esboços do processo projetivo feito em ipad e em tablets opacas. Fonte: os autores, 2012.

as diversas lógicas de pensamento e de linguagem se contagiassem e possibilitassem um desdobramento em novos processos cognitivos.

\section{Protocolos de análise}

Para analisar os resultados do workshop e de seus objetivos, foram adotados dois tipos de protocolos (Tang, 2010): o concorrente, no qual foram anotadas as impressóes dos participantes por meio de relatórios parciais e fotografias durante o processo e o protocolo de análise retrospectivo, por meio do qual os alunos fizeram um relato escrito das impressóes sobre as atividades após terem concluído o projeto (Figura 1). Ambos os protocolos pautaram-se em dois paradigmas: os objetivos do projeto/processo e as reflexóes individuais/comportamentais dos participantes. Assim, embora a meta do processo tinha como resultado um projeto, o objetivo do mesmo expandia-se sobre a observaçáo do modo como os alunos operaram para o alcance de seus resultados.

Durante o processo foram feitas as seguintes análises: observação de como os equipamentos estavam sendo utilizados (registros individuais em relatórios diários); compreensão dos padrôes de açôes (desempenho e potencialidade das ferramentas); alcance dos objetivos (relatórios finais) e identificação da atividade como método de pesquisa.

\section{Resultados}

A tablet gráfica ( $i$ Pad-Apple $\left.{ }^{(}\right)$se caracteriza como uma plataforma onde sáo propostos aplicativos constantemente. $\mathrm{Na}$ área de desenho é possível observar um uso e apropriação considerável na produção de ilustração digital, mas pouco explorada na proposição de projetos em arquitetura e urbanismo. Dentro de uma lógica de concessão ao meio físico, pela proximidade ao movimento da máo, nesse meio é simulado em sua tela uma "prancheta" de desenho. No entanto, algumas especificidades foram notadas como significativas durante o experimento. A sensibilidade de registro digital do movimento, seja pela caneta seja pela ponta do dedo, registra apenas a velocidade do movimento. Como resultado temos uma variabilidade de qualidades gráficas inscritas nesse aspecto. Não há registro algum da pressão sobre a superfície. A sensação de que se pode ter tudo a alguns toques de distância no iPad tem como contraponto a pequena área de trabalho (formato menor que o A4). O iPad é usado com uma "caneta" cuja ponta de borracha dificulta a precisáo do toque na tela.. No decorrer dos trabalhos do workshop percebeu-se o uso do recurso do zoom para compensar a impossibilidade do desenho dos detalhes. Essa característica, ao distanciar o ambiente de trabalho da similaridade ao meio físico, indicia os caminhos da contribuição do meio digital. Essas operaçóes permitiam recortes, ampliaçóes, uso de camadas. As operaçóes próprias dos computadores de mesa agora na versão portátil.

A tablet opaca (Wacon-Bamboo ${ }^{(}$) é uma espécie de "mouse em formato de mesa-caneta". Com uma caneta de ponta precisa, desenha-se sobre uma tela opaca e a imagem é reproduzida na tela do computador. Diferentemente do iPad, a tablet opaca não opera sem um computador. Porém, ao ser acoplado a um, permite o uso de todos os programas suportados pelo computador. A necessidade de se olhar para a tela do computador enquanto se desenha na mesa, faz com que a execução dos traços seja pouco precisa e, num primeiro momento, intuitiva, como em um desenho cego. O grupo de alunos tiveram um tempo de aprendizado relativamente curto, demonstrando a preferência por esse meio para o desenvolvimento da proposta, em função da precisão alcançada após o domínio da ferramenta. Os recursos dos editores de imagens somados à fluidez do traço tornam dinâmica a experiência de projetar no computador, onde, aumentar, repetir e distorcer formas, usar fotos de referência, sobrepor imagens tornam-se funçóes que agregam valores qualitativos aos trabalhos. O desempenho dos softwares de ediçáo de imagens possibilita um pensamento rápido, análogo ao croqui, ao mesmo tempo em que agrega um rigor formal que facilita a elaboração da sequência de formas. $\mathrm{O}$ uso da tablet opaca como periférico de um computador de mesa permitiu o uso de programas para a captura em vídeo das açôes desenvolvidas, possibilitando a produçáo de dados para as análises pautadas pelo protocolo concorrente.

Quanto às experimentações gráficas os três grupos utilizaram e exploraram a possibilidade de se desenhar sobre as fotos do local de inserçáo dos projetos, (tanto na fase dos croquis, como na apresentação final) testando as possibilidades. Percebe-se pelos material produzido pelos alunos que esse recurso reativa as práticas tradicionais sobre fotografias e reproduçôes xerográficas das mesmas. No entanto, o que antes era produto de uma análise pautada pela memória no ambiente dos escritórios e ateliers escolares, visto o hiato entre a tomada da imagens e sua ampliação, no experimento a análise é simultânea à própria experiência do lugar. Acredita-se em um ganho significativo, pois o que antes era caracterizado pela fragmentação dos diversos meios (registros escritos, desenhos, fotografias) que ganhariam uma posterior síntese, agora a síntese ao ser realizada no momento da observação potencializa a ampliação dos aspectos a serem considerados para a atividade projetual. Mantêm-se ainda a qualidade de registro para uma consulta posterior com o distanciamento crítico da experiência, só que com uma maior quantidade de variáveis e melhor qualificadas. 
Os recursos de desenho próprios aos dispositivos de captura digital de movimento humano ainda são definidos na proximidade com os recursos de desenho em suporte físico. O material produzido pelos alunos, pela sua diversidade de posturas exploratórias dos meios, permitem identificar os limites e inovaçóes desse processo de concessão de um meio em relação ao outro. Assim como outros materiais (tintas e grafite) o gesto não dialoga com as materialidades mas com a forma da linha e seu movimento (velocidade nas tablets gráficas e velocidade e pressão nas tablets opacas). Acreditando estar "pintando" como em papel, percebeu-se os alunos caminhando em direção a uma nova linguagem gráfica com particularidades muito precisas. Uma observaçáo rápida e superficial pode se equivocar ao acreditar que se trata das mesmas lógicas de codificação e expressão das usadas nos meios físicos.

\section{0 projeto como produto do workshop}

Analisando os objetivos/ metas do projeto, os três grupos desenvolveram seus trabalhos de formas distintas (Figura 3): o grupo 1 optou por trabalhar desde o início com a modulação do cubo, assim, os croquis, estudos e propostas conseguiram manter uma unidade do sistema; o grupo 2 pautou-se na referencia projetual (De Stijl) e utilizou esta aproximaçáo como elemento estruturador do sistema; o grupo 3 iniciou seu processo a partir da desconstrução do cubo para a criação de novas estruturas.

A variedade de partidos projetuais, bem como seu desenvolvimento projetual, indicia que ao se utilizar um processo digital de desenho que se fundamenta na captura do movimento humano e se distancia das mediaçóes dos comandos complexos dos programas paramétricos e vetoriais, a influência plástica desses meios na qualidade gráfica dos produtos é consideravelmente reduzida. Tal fato observado assume sua importância como parâmetro ao debate sobre o apagamento da autoria em função das condicionantes das qualidades gráficas dadas pelos recursos dos softwares. Mais que o resgate da autoria, o que se possibilita é a retomada do processo de representação como um momento importante na definição das características conceituais das propostas.

\section{Considerações finais}

Diante das novas tecnologias é inevitável que o ensinar a desenhar e a projetar, sofra transformaçóes. As práticas e procedimentos do desenho podem ser revistos no sentido de incorporar as novas ferramentas digitais, sem que se percam suas virtudes seculares. Embora o elenco de contribuiçóes evidenciadas durante o workshop tenha sido importante para o uso e a aplicabilidade das tablets, a maior contribuição deste texto é trazer à tona a discussão dos desenhos digitais. Pode-se inferir que desenhar em uma tablet não tem o mesmo significado do ato de desenhar no papel, pois as relaçôes entre o desenhador e o desenho não são mais as mesmas. O olhar e a percepção são instantaneamente modificadas, seja pela captura da imagem, um híbrido entre mídias, seja pela própria feitura do desenho com suas infinitas possibilidades de recursos, como também pelas alteraçóes de escala do objeto desenhado. Sem se falar que em ambiente dotado de wi-fi, permitiu um trabalho colaborativo enriquecedor no processo projetivo. As tablets se apresentam como instrumento de conexão entre o desenho analógico e o digital: ela é capaz de captar a pressão e a velocidade empregada pelo traço aproximando o processo de teclar no computador à imprecisáo e ambiguidade do gesto próprio ao desenho à mão livre. É importante apontar que não se trata de uma simples alteração de suporte, do papel à tela do tablet, mas a possibilidade de uma sinergia entre duas lógicas de grafias. $\mathrm{O}$ processo de sistematizaçáo próprio dos softwares pode ser contagiado pelo imediatismo do desenho à mão livre, e este ter seu processo de reconstrução significante potencializado por meio das ediçôes digitais.

\section{Agradecimentos}

Agradecemos o Instituto de Arquitetura e Urbanismo pela infraestrutura, ao Conselho Nacional de Pesquisa (CNPq) pelo financiamento da pesquisa e ao N.ELAC pela organização e execuçáo do workshop.

\section{Referencias}

Celani, G.; Godoi, G.; Rodrigues, G. (2007). O processo de projeto arquitetônico mediado por computador: um estudo de caso com o Architectural Desktop. GRAPHICA. Curitiba.

Chan, C. S. (1990). Cognitive process in architectural design problem solving. In Design Studies, vol 11, no. 2.

Eça (2003), Teresa. Desenho sem corpo? Desenho na era dos “cyborgs". PSIAX no2. Texto 8. Porto, Portugal. p.49-52.

ELLIOTT, A.; HEARST, M. A. 2002. A Comparison of the Affordances of a Digital Desk and Tablet for Architectural Image Tasks. International Journal of Human-Computer Studies. Volume 56 (2) (pp 173-197). Academic Press, Minessota, EUA

GOUVEIA, A. P. S. O croqui do arquiteto e o ensino do desenho. Tese apresentada à FAUUSP para obtenção do título de Doutor. FAUUSP, 1998.

KAVAKLI, M. Structure in idea sketching behaviour Faculty of Architecture. Design studies, Turquia, 1998.

LASEAU, Paul. Graphic Thinking for Architects \& Designers. Third edition. United States of America, 1982.

Mitchell, W. J.; McCullough, M.. 1991. Digital Design Media. New York: Van Nostrand Reinhold.

RIGHI, T. A .F; Celani, G. Esboços na era digital: uma discussão sobre as mudanças na metodologia de projeto arquitetônico. Congresso Iberoamericano de gráfica digital SIGRADI. In Anais... Havana Cuba 2008.

Tang, H. H. (2011). Comparing collaborative co-located and distributed design processes in digital and traditional sketching environments: a protocol study using the function - behavior structure coding scheme. In Design Sutdies, Elservier, 32, 1-29.

URIA, L. Expansión y crisis Del dibujo - Reflexiones sin imágenes. In Revista EGA Expresión gráfica arquitectónico no 12 año 12/2007. 